\title{
Comparação de métodos diretos de extração e quantificação dos teores de clorofilas em folhas do capim-Tifton 85
}

\author{
Comparison of direct methods of extraction and chlorophyll contents quantification in leaves \\ of Tifton 85 bermudagrass
}

\author{
Élio Barbieri Junior ${ }^{{ }^{*}}$ Roberto Oscar Pereyra Rossiello ${ }^{\mathrm{I}}$ Mirton José Frota Morenz ${ }^{\mathrm{I}}$ \\ Roberta Cristiane Ribeiro ${ }^{\mathrm{II}}$
}

\begin{abstract}
O objetivo deste estudo foi verificar qual é o melhor protocolo para extração das clorofilas $a, b$ e total $(a+b)$ a ser aplicado em estudos com a gramínea forrageira Tifton 85 (Cynodon spp.). Os resultados revelaram que os melhores extratores, tomando-se como base os teores de clorofila total $(a+b)$, foram o $N, N$-dimetilformamida, o dimetilsulfóxido e a acetona 80\% (com as equações propostas por ARNON, 1949). A variação temporal dos teores das clorofilas $a, b$ e total ajustaram-se a um modelo hiperbólico comum a todos os solventes, sendo o período de 48 horas considerado suficiente para uma adequada extração.
\end{abstract}

Palavras-chave: Cynodon spp., acetona, $N, N$-dimetilformamida, dimetilsulfóxido.

\section{ABSTRACT}

This study aimed to assess which is the most appropriate protocol for extraction of chlorophylls $a, b$ and total $(a+b)$ to be applied in studies with Tifton 85 (Cynodon spp.) forage grass. Results revealed that, based on total $(a+b)$ chlorophyll contents, the best extractors were $\mathrm{N}, \mathrm{N}$ dimethylformamide, dimethylsulfoxide and acetone 80\% (using the equations proposed by ARNON, 1949). Temporal changes in the concentrations of chlorophyll $a, b$ and total were well described by a hyperbolic model common to all solvents, being the period of 48 hours considered sufficient for an appropriate extraction.

Key words: Cynodon spp., acetone, $N, N$-dimethylformamide, dimethylsulfoxide.
As clorofilas exercem um controle dominante sobre a quantidade de radiação solar absorvida pelas plantas e por essa via as suas concentrações foliares guardam uma estreita relação com as taxas fotossintéticas e a produtividade primária (STREIT et al., 2005; BLACKBURN, 2007).

De forma geral, as principais fontes de variação associadas à extração dos pigmentos clorofilianos incluem a natureza, polaridade e grau de pureza do solvente (RITCHIE, 2008), a temperatura e o tempo de incubação (TAIT \& HIK, 2003), e as equações utilizadas para calcular as concentrações das clorofilas (PORRA, 2002). Além disso, tem sido observado que a abundância dessas moléculas varia de acordo com a espécie vegetal, o que demanda ajustes metodológicos para que a extração e conservação desses pigmentos ocorram com a máxima eficiência (CRUZ et al., 2007). Em função da variedade de procedimentos experimentais disponíveis e da falta de informações mais detalhadas sobre a utilização destes em gramíneas forrageiras do gênero Cynodon, foi realizado um estudo visando a seleção do melhor protocolo, considerando diversos solventes, tempos de extração e equações características para a determinação espectrométrica das clorofilas $a, b$ e total em folhas do capim-Tifton 85 .

As amostras de folhas foram coletadas em parcelas experimentais oriundas de um estudo de aspectos nutricionais e produtivos do capim-Tifton 85

\footnotetext{
'Programa de Pós-graduação em Zootecnia, Universidade Federal Rural do Rio Janeiro (UFRRJ), 23890-000, Seropédica, RJ, Brasil. E-mail: eliobarbieri@yahoo.com.br.*Autor para correspondência.

"Programa de Pós-graduação em Química, UFRRJ, Seropédica, RJ, Brasil.
} 
no Campus da Universidade Federal Rural do Rio de Janeiro (UFRRJ), em junho de 2008. Todas as folhas amostradas foram provenientes de dosséis que tinham recebido, no curso do ano anterior, $450 \mathrm{~kg}^{-1} \mathrm{ha}^{-1}$ ano de $\mathrm{N}$, na forma de ureia, além de quantidades apropriadas de $\mathrm{P}, \mathrm{K}, \mathrm{Ca}$ e Mg, de acordo com a análise de solo. A determinação dos teores de clorofilas foi realizada na primeira folha expandida, a partir do ápice, apresentando aurícula visível (dewlap) dos perfilhos expostos ao sol no momento da amostragem. Procedeu-se à extração de discos de 6,0mm de diâmetro, com auxílio de um furador manual, em 10 lâminas escolhidas ao acaso (1 disco/folha). O material coletado foi rapidamente transferido para frascos de vidro, previamente revestidos com papel alumínio para excluir luminosidade, contendo $20 \mathrm{ml}$ dos respectivos extratores. Os frascos foram vedados com rolhas de borracha e lacrados com filme de parafina $\left(\right.$ Parafilm $\left.^{\circledR}\right)$. Foram comparados cinco protocolos de extração e quantificação: acetona 80\%, segundo ARNON (1949), modificado pela supressão das etapas de trituração e centrifugação dos discos, ou segundo PORRA et al. (1989); dimetilsulfóxido (DMSO) (BARNES et al., 1992) sob temperatura ambiente (CRUZ et al., 2007); etanol absoluto (WINTERMANS \& DE MOTS, 1965); e N,Ndimetilformamida (DMF) (MORAN, 1982). No laboratório, os frascos foram mantidos no escuro, enquanto analisados repetidamente, com intervalos de 12 horas, totalizando oito avaliações sequenciais realizadas às $12,24,36,48,60,72,84$ e 96 horas. As absorbâncias dos extratos, variáveis entre 645-665nm (dependendo de método e classe de clorofila), foram analisadas em Espectrofotômetro da marca Biospectro e modelo SP 220. Durante o período de extração, a temperatura ambiente oscilou entre $23-26^{\circ} \mathrm{C}$, e a umidade relativa oscilou entre $40-75 \%$. Todas as equações utilizadas fornecem os teores das clorofilas em unidades de $\mu \mathrm{g} \mathrm{ml}^{-1}$. Considerando-se o volume do extrator, a área foliar extraída $\left(282,74 \mathrm{~mm}^{2}\right.$ de tecido verde) e a massa molar das clorofilas a e b, os teores foram recalculados e expressos em $\mu \mathrm{mol} \mathrm{m} \mathrm{m}^{-2}$ da lâmina foliar. Os resultados foram analisados dentro de um delineamento inteiramente casualizado, com cinco repetições, envolvendo um fator qualitativo (método de extração) e outro quantitativo (tempo de extração). $\mathrm{O}$ fator qualitativo foi analisado por meio de análise de variância convencional, enquanto o quantitativo foi abordado por meio de regressão não linear, segundo os modelos disponíveis no software GraphPad Prism v. 5.0 (MOTULSKY \& CHRISTOPOULOS, 2004).

Os resultados da comparação, expressos como valores médios dentro do período 12-96 horas, são apresentados na tabela 1 . O maior teor de clorofila $a$ foi obtido com DMSO, seguido pelo DMF, não havendo, entretanto, diferença significativa entre eles (teste Scott-Knott, $\mathrm{P}<0,05)$. A menor recuperação de clorofila $a$ em relação ao DMSO $(-23 \%, \mathrm{P}<0,05)$ correspondeu ao método de PORRA et al. (1989). Para a clorofila $b$, os resultados favoreceram a acetona $80 \%$, utilizando as equações propostas por ARNON (1949), enquanto a menor recuperação correspondeu à extração com DMSO, o que evidencia ineficiência do solvente para a extração completa desse pigmento. Para clorofila total $(a+b)$, as melhores extrações quantitativas corresponderam aos métodos DMF (MORAN, 1982), DMSO (BARNES et al., 1992) e Acetona 80\% (ARNON, 1949), os quais não diferiram significativamente entre si (Tabela 1). Do mesmo modo que o verificado para a clorofila $a$, a equação de PORRA et al. (1989), para a clorofila total, resultou no menor teor absoluto entre os métodos testados. Isso confirma que as equações associadas a cada um dos métodos representam um fator importante na escolha do protocolo de extração. Ressalte-se também o baixo desempenho do álcool absoluto (WINTERMANS \& DE MOTS, 1965) como extrator em folhas de Tifton 85 . Esse resultado, contrário à experiência de outros autores (RITCHIE, 2008), ratifica o caráter altamente específico dos métodos de quantificação de clorofilas.

Tabela 1 - Teores médios ( \pm desvio padrão) das clorofilas $a, b$ e total $(a+b)$ extraídas de lâminas foliares de Cynodon spp., cultivar 'Tifton 85 ', em função de cinco protocolos operacionais.

\begin{tabular}{|c|c|c|c|}
\hline Método & Clorofila $\left.a(\mu \mathrm{mol} \mathrm{m})^{-2}\right)$ & Clorofila $b\left(\mu \mathrm{mol} \mathrm{m}{ }^{-2}\right)$ & Clorofila $(a+b)\left(\mu \mathrm{mol} \mathrm{m}^{-2}\right)$ \\
\hline Dimetilsulfóxido $^{(1)}$ & $316 \pm 2,93 \mathrm{~A}^{(6)}$ & $66 \pm 1,41 \mathrm{C}$ & $383 \pm 3,70 \mathrm{~A}$ \\
\hline $\mathrm{N}, \mathrm{N}$ Dimetilformamida ${ }^{(2)}$ & $297 \pm 3,58 \mathrm{~A}$ & $85 \pm 2,03 \mathrm{~B}$ & $383 \pm 5,13 \mathrm{~A}$ \\
\hline Acetona $80 \%^{(3)}$ & $250 \pm 2,65 \mathrm{~B}$ & $111 \pm 1,50 \mathrm{~A}$ & $361 \pm 4,05 \mathrm{~A}$ \\
\hline Álcool absoluto ${ }^{(4)}$ & $259 \pm 2,84 \mathrm{~B}$ & $84 \pm 2,25 \mathrm{~B}$ & $343 \pm 3,86 \mathrm{~B}$ \\
\hline Acetona $80 \%{ }^{(5)}$ & $242 \pm 2,55 \mathrm{~B}$ & $81 \pm 1,18 \mathrm{~B}$ & $324 \pm 3,62 \mathrm{~B}$ \\
\hline
\end{tabular}

(1) BARNES et al. (1992); ${ }^{(2)}$ MORAN (1982); ${ }^{(3)}$ ARNON (1949) modificado; ${ }^{(4)}$ WINTERMANS \& DE MOTS (1965); e ${ }^{(5)}$ PORRA et al. (1989). ${ }^{(6)}$ Médias seguidas pela mesma letra na coluna não diferem significativamente pelo teste de Scott-Knott $(\mathrm{P}<0,05)$. Seropédica, RJ, junho de 2008 . 
Em relação ao tempo de extração, outro importante ponto nos protocolos analíticos (TAIT \& HIK, 2003), observou-se que o padrão de variação temporal para as três classes de clorofilas ajustou-se a um mesmo modelo, independentemente do método de extração (Figuras 1A a 1E). O modelo corresponde a uma hipérbole retangular, a qual se inicia em $\mathrm{y}=0$ para $\mathrm{x}=0$, sendo utilizado para descrever a cinética de saturação de um ligante ao seu substrato (MOTULSKY \& CHRISTOPOULOS, 2004). No presente caso, os ajustes foram altamente eficientes, como evidenciam a maioria dos valores de $\mathrm{R}^{2}$ acima de 0,95 , salvo exceções, todas relacionadas à clorofila $b$ (Figuras $1 \mathrm{~A}, 1 \mathrm{C} \mathrm{e} 1 \mathrm{E})$. Também é interessante observar, em todos os casos, a estabilidade dos valores acima de 48 horas, o que sugere uma efetiva "saturação" do processo de
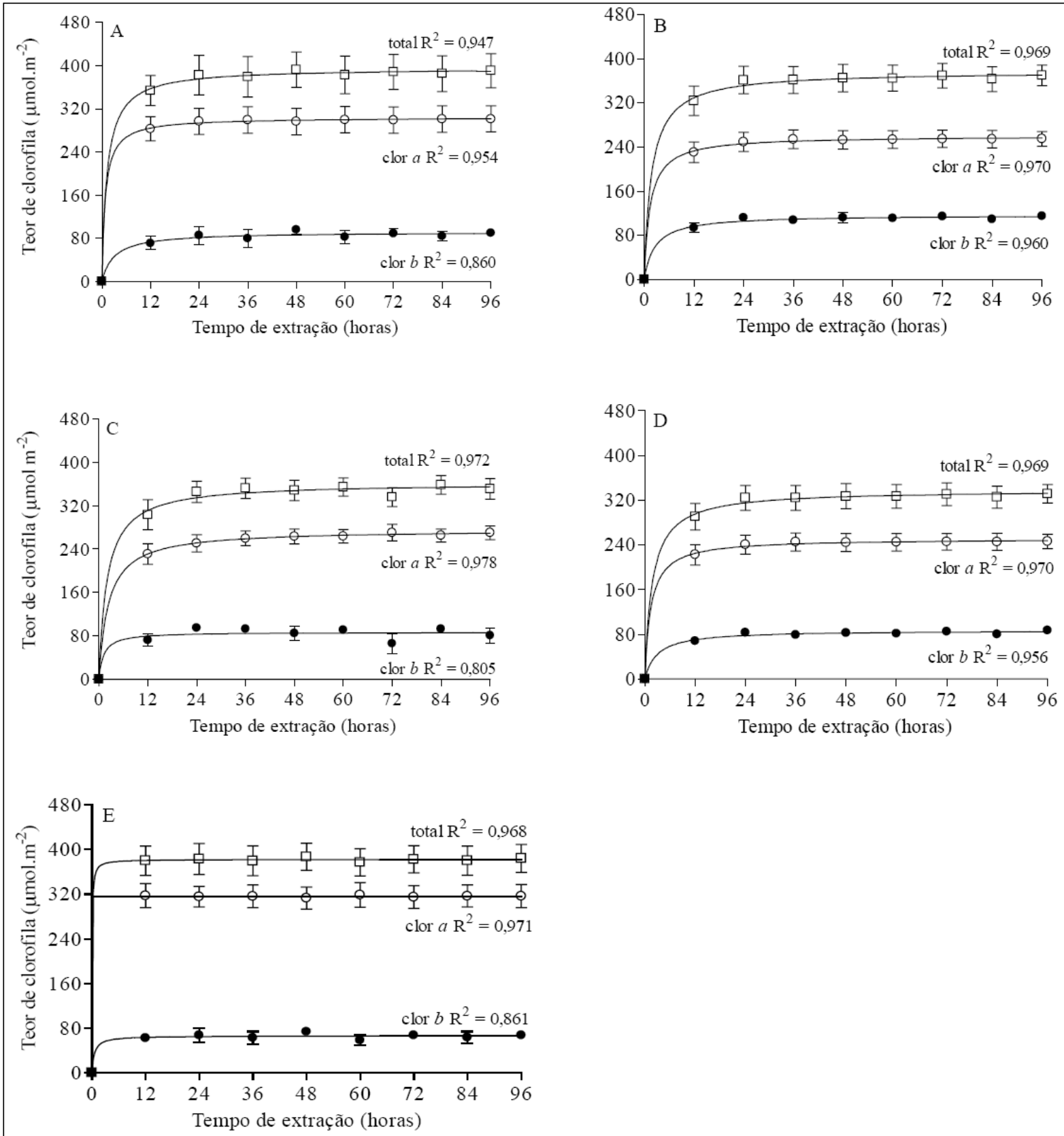

Figura 1- Teores das clorofilas $a, b$ e total $(a+b)$ extraídas de discos foliares de folhas de Tifton 85 , por cinco protocolos diferentes, em função do tempo de extração. A: N,N-dimetilformamida (MORAN, 1982); B: acetona 80\% (ARNON, 1949); C: álcool absoluto (WINTERMANS \& DE MOTS, 1965); D: acetona 80\% (PORRA et al., 1989); e E: dimetilsulfóxido (BARNES et al., 1992) 
extração, independentemente de solvente. Assim, dentro das condições operacionais do presente trabalho, esse tempo de extração (48 horas) foi considerado o mais prudente e seguro. É possível que, com procedimentos adicionais, tais como aquecimento das amostras (BARNES et al., 1992) ou centrifugação (TAIT \& HIK, 2003), os tempos de incubação possam ser diminuídos ou a eficiência de extração possa ser aumentada. Tais protocolos deveriam ser preferidos em estudos mais aprofundados, envolvendo aspectos bioquímicos ou fisiológicos, específicos a cada classe de clorofila. Entretanto, quando se trata da definição de protocolos operacionais sob condições de campo, envolvendo a comparação de elevado número de tratamentos e repetições, é admissível perder certa parcela de precisão, sem comprometer, todavia, o rigor das comparações.

Sendo assim, tomando-se como base a clorofila total $(a+b)$ em lâminas foliares da gramínea forrageira Tifton 85 , os melhores extratores foram a N,Ndimetilformamida, o dimetilsulfóxido e a acetona $80 \%$, com 48 horas de incubação.

\section{REFERÊNCIAS}

ARNON, D.I. Copper enzymes in isolated chloroplasts. Polyphenoloxidase in Beta vulgaris. Plant Physiology, v.24, n.1, p.1-15, 1949.

BLACKBURN, G.A. Hyperspectral remote sensing of plant pigments. Journal of Experimental Botany, v.58, n.4, p.855867, 2007. Disponível em: <http://jxb.oxfordjournals.org/cgi/ content/abstract/58/4/855>. Acesso em: 16 dez. 2009. doi: $10.1093 / \mathrm{jxb} / \mathrm{erl} 123$.

BARNES, J.D. et al. A reappraisal of the use of DMSO for the extraction and determination of chorophylls $a$ and $b$ in lichens and higher plants. Environmental and Experimental Botany, v.32, n.2, p.85-100, 1992.

CRUZ, A.C.F. et al. Métodos comparativos na extração de pigmentos foliares de três híbridos de Bixa orellana L. Revista Brasileira de Biociências, v.5, Sup1.2, p.777-779, 2007.
MORAN, R. Formulae for determination of chlorophyllous pigments extracted with $\mathrm{N}, \mathrm{N}$-dimethylformamide. Plant Physiology, v.69, n.6, p.1376-1381, 1982.

MOTULSKY H.J.; CHRISTOPOULOS A. Fitting models to biological data using linear and non-linear regression. A practical guide to curve fitting. In Oxford University Press 2004 Oxford, UK:Oxford University, 2004. 351p.

PORRA, R.J. et al. Determination of accurate extinction coefficients and simultaneous equations for assaying chlorophylls $a$ and $b$ extracted with four different solvents: verification of the concentration of chlorophyll standards by atomic absorption spectrometry. Biochimica et Biophysica Acta, v.975 n.3, p.384-394, 1989.

PORRA, R.J. The chequered history of the development and use of simultaneous equations for the accurate determination of chlorophylls $a$ and $b$. Photosynthesis Research, v.73, n.1-3, p.149-156, 2002.

RITCHIE, R.J. Universal chlorophyll equations for estimating chlorophylls $a, b, c$, and $d$ and total chlorophylls in natural assemblages of photosynthetic organisms using acetone, methanol, or ethanol solvents. Photosynthetica, v.46, n.1, p.115-126, 2008. Disponível em: <http://www.springerlink.com/ content/8163013p214176x3/>. Acesso em: 16 dez. 2009. doi: 10.1007/s11099-008-0019-7.

STREIT, M.N. et al. As clorofilas. Ciência Rural, v.35, n.3, p.748-755, 2005. Disponível em: <http://www.scielo.br/ scielo.php?pid $=$ S0103-84782005000300043\&script $=$ sci_arttext $>$. Acesso em: 16 dez. 2009. doi: $10.1590 / \mathrm{S} 0103-$ 84782005000300043 .

TAIT, M.A.; HIK. D.S. Is dimethylsulfoxide a reliable solvent for extracting chlorophyll under field conditions? Photosynthesis Research, v.78, n.1, p.87-91, 2003. Disponível em: <http://www.springerlink.com/content/ mp46875712518092/>. Acesso em: 16 dez. 2009. doi: 10.1023/ A: 1026045624155 .

WINTERMANS, J.F.G.M.; DE MOTS, A. Spectrophotometric characteristics of chlorophyll and their pheophytins in ethanol. Biochimica et Biophysica Acta, v.109, n.2, p.448-453, 1965. 